\title{
Get off my back! Inferior vena cava filter erosion into the lumbar spine
}

\author{
Jacob Mathew, ${ }^{\oplus 1}$ Michael R Povlow, ${ }^{2}$ Allen Fong ${ }^{1}$
}

${ }^{1}$ Department of Internal Medicine, US Army Brooke Army Medical Center, Fort Sam Houston, Texas, USA

${ }^{2}$ Department of Radiology, US Army Brooke Army Medical

Center, Fort Sam Houston, Texas, USA

Correspondence to Dr Jacob Mathew Jr, drjacobmathewj@gmail.com

Accepted 27 May 2019

\section{DESCRIPTION}

We present the case of an 84-year-old woman with a medical history of both provoked and

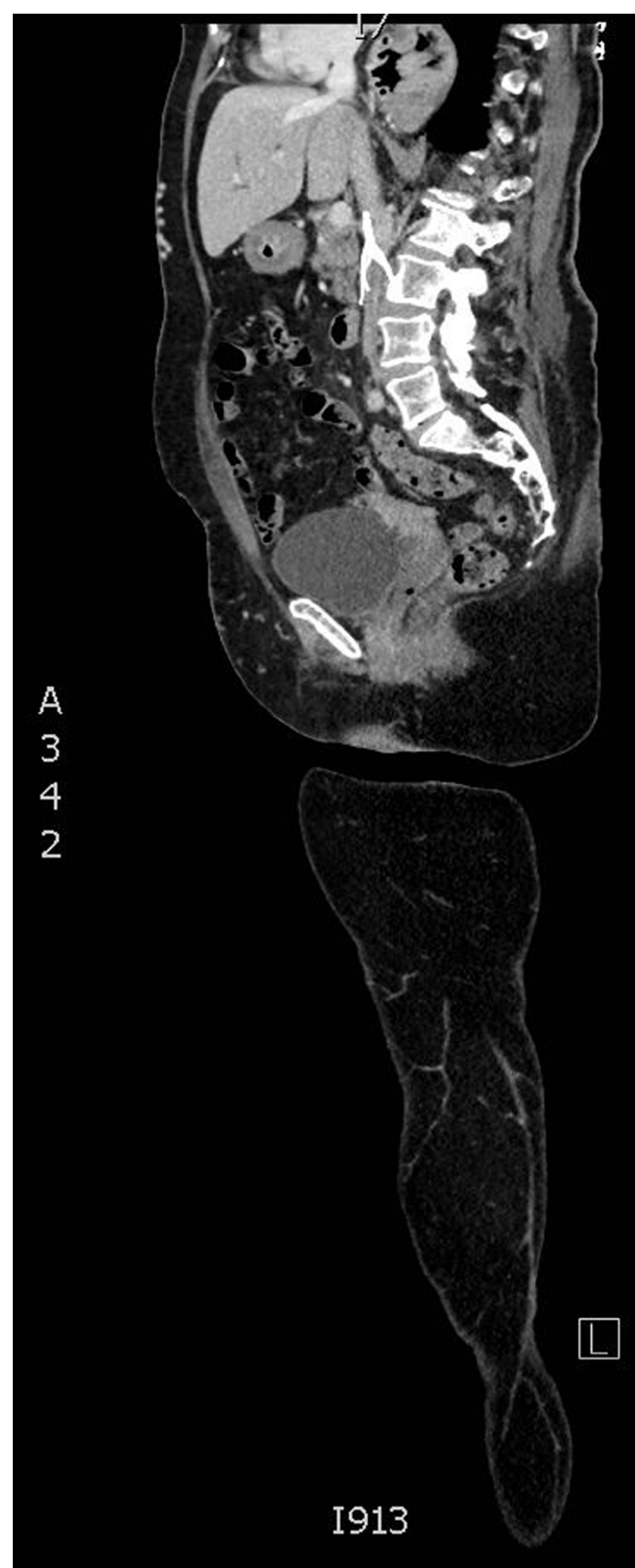

Figure 1 CT of the abdomen and pelvis with intravenous contrast, sagittal plane, showing an inferior vena cava filter with the posterior most limb of the filter traversing the caval wall, terminating in the L3 vertebral body. unprovoked deep venous thromboembolisms and heterozygosity for Factor V Leiden, on chronic rivaroxaban $20 \mathrm{mg} /$ day, who was seen at our institution with increasing left leg swelling and discomfort. On examination, she was breathing and resting comfortably. She had slight increased circumference of the left lower extremity in relation to the right lower extremity with tenderness to palpation. Positive Homan and Lisker's sign were noted. Dorsalis pedis and posterior tibialis pulses were two out of four in both lower extremities. On questioning, she denied any recent long distance travel or trauma (to include surgery) and did not miss any doses of her rivaroxaban. She had no family history of bleeding diathesis or thrombotic events. Her surgical history was notable for the placement of an inferior vena cava filter (IVCF) in 2015 due to deep vein thrombosis (DVT) in the setting of a concurrent gastrointestinal bleed (which prohibited the use of therapeutic anticoagulation at that time). Vital signs were stable, and the patient did not look unwell. She had a normal haemoglobin, haematocrit, platelet count and coagulation laboratory panel. Deep venous ultrasound of the left lower extremity revealed evidence of DVT extending from the left common femoral vein to the left popliteal vein. Given the presumed failure of rivaroxaban, she was transitioned to a heparin drip on admission. Review of her medical chart (to include prior CT imaging from 2017 of the abdomen and pelvis) revealed the posterior limb of the IVCF traversing the caval wall and terminating and embedded in the L3 vertebral body (figure 1). Vascular surgery was consulted due to the concern for potential retroperitoneal bleed due to her concurrent heparin drip. Given the chronicity of the findings, and lack of symptoms otherwise, surgical intervention was not considered emergent and instead, repeat imaging was recommended. As can be seen in figure 2, repeat imaging showed no significant progression or worsening of the position of the IVCF. Given its unchanged appearance, and her current thrombotic episode, no surgical intervention was advised. The patient was ultimately discharged on dabigatran with close vascular surgery follow-up.

IVCFs are devices that capture propagating thrombi from the lower extremities to the pulmonary arteries. $^{1-3}$ Placement is considered in a select group of patients with a contraindication to anticoagulation who are found to have venous thromboembolism at high risk for recurrence and/or propagation to pulmonary embolism..$^{3-5}$ Such contraindications include active gastrointestinal bleed (as in our patient's history), cerebral 


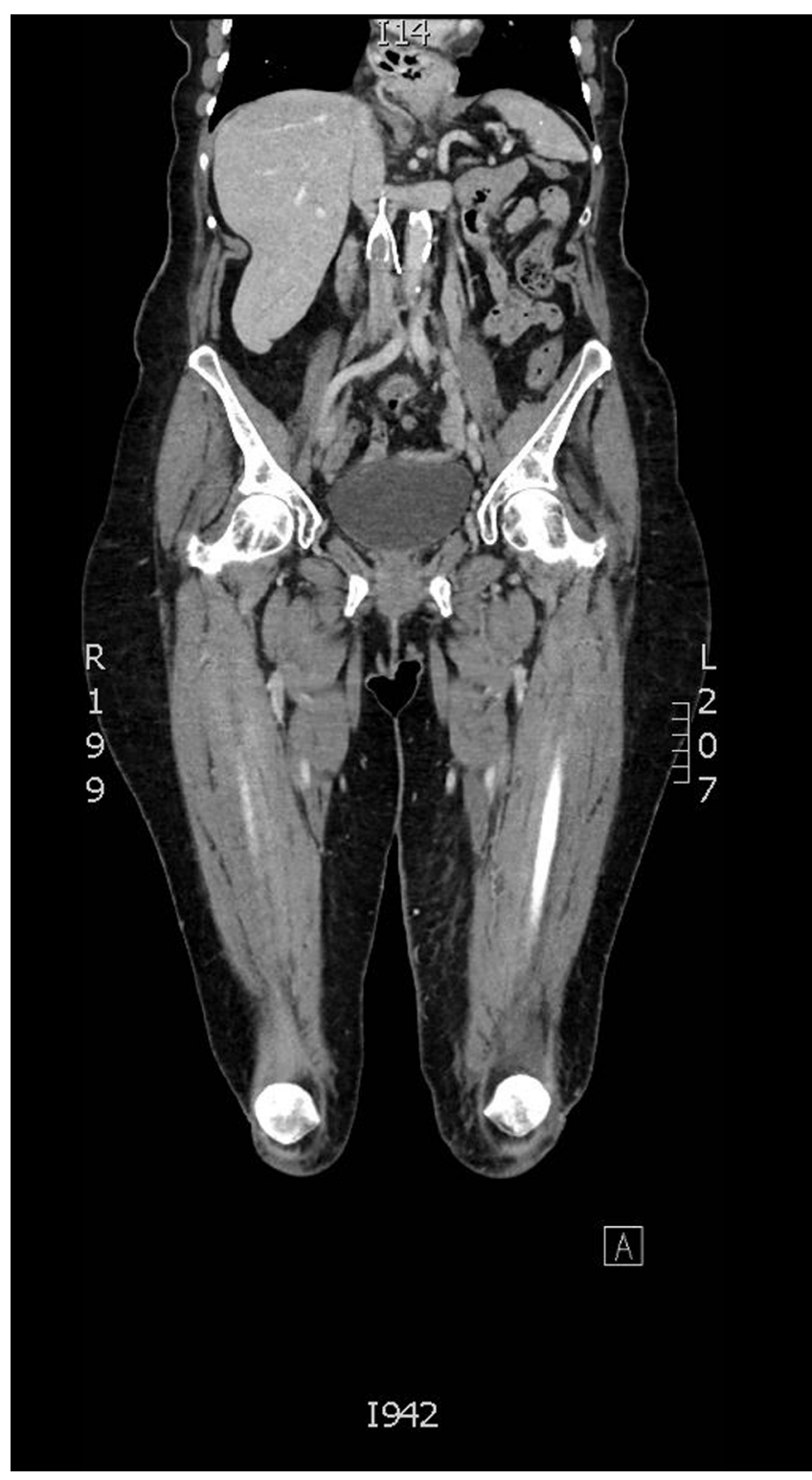

Figure $2 \mathrm{CT}$ of the abdomen and pelvis with intravenous contrast, coronal plane, showing an unchanged position of the IVCF with multiple tines outside the IVC including one within the anterior inferior aspect of the L3 vertebral body. IVC, inferior vena cava filter.

haemorrhage and haemorrhagic stroke among others. ${ }^{4}$ There are two major types: retrievable and permanent. ${ }^{6}$ Since their introduction in the late 1990's, the placement of retrievable IVCFs has risen in part due to reportedly lower complication rates than permanent filters, which associated with an increased incidence of recurrent DVTs, filter migration, caval wall perforation, thrombosis, infection, pulmonary emboli and filter fracture. ${ }^{24-9}$ Despite limited evidence supporting their ability to truly prevent life-threatening pulmonary emboli, and association instead, with recurrent DVTs, IVCFs continue to be placed in patients with absolute contraindications to anticoagulation. ${ }^{1011}$ As a result, the Federal Drug Administration recommends that both retrievable and permanent filters be removed within 59 days of insertion once the risk for pulmonary embolism has resolved. ${ }^{6}{ }^{9}$ In our case, the discovery of a retained IVCF more than 2 years after its original insertion was not surprising as retrieval rates of filters has not matched the uptick in their insertion. ${ }^{6}$ In our case, due to the complexity of the surgery and her comorbidities, she was discharged on anticoagulation with outpatient follow-up with her vascular surgeon to further discuss safe IVCF removal.

In summary, while controversial, inferior vena cava filters remain an option in a select group of patients with contraindications to anticoagulation whom the care team feels have an unacceptably high risk of thrombi propagation from the lower extremities. It is important for providers who are considering offering this treatment option to patients to understand the inherent risk the device poses to the patient and the complications that have been clearly reported in literature which include the development of pulmonary emboli and recurrent DVT. All filters, regardless of type, have been shown to pose risks to the patient when kept long term and thus require consistent re-evaluation by clinicians to ensure of their removal when clinically feasible.

\section{Learning points}

- While controversial, inferior vena cava filter placement should only be considered in patients with a high risk of thromboembolic disease but contraindications to systemic anticoagulation, given the significant risk the device poses to the patient.

- Regardless of the type of filter placed, a clear plan prior to, or on placement, aimed towards eventual removal within 59 days of insertion, should be established assuming the contraindication for anticoagulation has resolved.

Contributors JM: substantial contributions to conception and design, acquisition of data, analysis and interpretation of data, drafting the article, revising it critically for important intellectual content and final approval of the version to be published. AF and MRP: substantial contributions to the acquisition of data, revising it critically for important intellectual content and final approval of the version to be published.

Funding The authors have not declared a specific grant for this research from any funding agency in the public, commercial or not-for-profit sectors.

Disclaimer The views expressed are those of the author and do not reflect the official policy or position of the US Army, Department of Defense or the US Government.

Competing interests None declared.

Patient consent for publication Obtained.

Provenance and peer review Not commissioned; externally peer reviewed.

\section{REFERENCES}

1 Eifler AC, Lewandowski RJ, Gupta R, et al. Optional or permanent: clinical factors that optimize inferior vena cava filter utilization. J Vasc Interv Radiol 2013;24:35-40.

2 Van Ha TG. Complications of inferior vena caval filters. Semin Intervent Radiol 2006;23:150-5.

3 Holly BP, Funaki B, Lessne ML. Inferior vena cava filters. Clin Chest Med 2018;39:645-50.

4 Sarosiek S, Crowther M, Sloan JM, Indications SJ. Indications, Complications, and Management of Inferior Vena Cava Filters. JAMA Intern Med 2013;173:513.

5 DeYoung E, Minocha J. Inferior vena cava filters: Guidelines, best practice, and expanding indications. Semin Intervent Radiol 2016;33:065-70.

6 Mylankal KJ, Fitridge R. Inferior vena cava filters: recent controversies. ANZ J Surg 2018;88:128-9.

7 Shang EK, Nathan DP, Carpenter JP, et al. Delayed complications of inferior vena cava filters: case report and literature review. Vasc Endovascular Surg 2011;45:290-4.

8 Grewal S, Chamarthy MR, Kalva SP. Complications of inferior vena cava filters. Cardiovasc Diagn Ther 2016;6:632-41.

9 Jia Z, Wu A, Tam M, et al. Caval penetration by inferior vena cava filters. Circulation 2015;132:944-52.

10 The PREPIC Study Group. Eight-year follow-up of patients with permanent vena cava filters in the prevention of pulmonary embolism. Circulation 2005;112:416-22.

11 Mismetti P, Laporte S, Pellerin 0, et al. Effect of a retrievable inferior vena cava filter plus anticoagulation vs anticoagulation alone on risk of recurrent pulmonary embolism: a randomized clinical trial. JAMA 2015;313:1627-35. 
Copyright 2019 BMJ Publishing Group. All rights reserved. For permission to reuse any of this content visit https://www.bmj.com/company/products-services/rights-and-licensing/permissions/

BMJ Case Report Fellows may re-use this article for personal use and teaching without any further permission.

Become a Fellow of BMJ Case Reports today and you can:

- Submit as many cases as you like

- Enjoy fast sympathetic peer review and rapid publication of accepted articles

Access all the published articles

Re-use any of the published material for personal use and teaching without further permission

Customer Service

If you have any further queries about your subscription, please contact our customer services team on +44 (0) 2071111105 or via email at support@bmj.com.

Visit casereports.bmj.com for more articles like this and to become a Fellow 